The Real Estate Risk Premium Puzzle: A Solution ${ }^{1}$

\author{
Ping Cheng \\ Department of Finance \\ Florida Atlantic University \\ 777 Glades Road, Boca Raton, FL 33431 \\ pcheng@fau.edu \\ Zhenguo Lin \\ Department of Finance and Economics \\ Mississippi State University \\ Mississippi State, MS 39762 \\ llin@cobilan.msstate.edu \\ Yingchun Liu \\ Department of Finance \\ Texas Tech University \\ Lubbock, TX 79409 \\ yingchun.liu@ttu.edu
}

\begin{abstract}
For decades, performance comparisons between real estate and financial assets have repeatedly indicated that private real estate investment exhibits significantly higher risk-adjusted returns than publicly traded financial assets such as common stocks. That is, there is an apparent "real estate risk premium puzzle." In this paper, we find that the seemingly superior risk-adjusted returns of real estate may be caused by inappropriate adoption of the conventional risk measure to real estate, a measure that completely ignores the non-i.i.d. nature of the asset's return distribution, as well as its illiquidity risk. We develop a modified performance measure - a Sharpe ratio for real estate - to capture the time-dependent nature of real estate risk by incorporating illiquidity risk in a closed-form formula. Our finding shows that, once the real estate risk is properly measured, the longstanding "real estate risk premium puzzle" no longer exists. Our approach also shows that real estate price risk over time can be accurately obtained through empirical estimation without relying on a simplification assumption of a particular distribution like the i.i.d. assumption.
\end{abstract}

\footnotetext{
${ }^{1}$ This paper won a best paper award by American Real Estate Society in 2008.
} 


\section{The Real Estate Risk Premium Puzzle: A Solution}

[Abstract] For decades, performance comparisons between real estate and financial assets have repeatedly indicated that private real estate investment exhibits significantly higher risk-adjusted returns than publicly traded financial assets such as common stocks. That is, there is an apparent "real estate risk premium puzzle." In this paper, we find that the seemingly superior risk-adjusted returns of real estate may be caused by inappropriate adoption of the conventional risk measure to real estate, a measure that completely ignores the non-i.i.d. nature of the asset's return distribution, as well as its illiquidity risk. We develop a modified performance measure - a Sharpe ratio for real estate-to capture the timedependent nature of real estate risk by incorporating illiquidity risk in a closed-form formula. Our finding shows that, once the real estate risk is properly measured, the long-standing "real estate risk premium puzzle" no longer exists. Our approach also shows that real estate price risk over time can be accurately obtained through empirical estimation without relying on a simplification assumption of a particular distribution like the i.i.d. assumption.

Key words: real estate performance, return and risk, time-on-market, illiquidity risk, portfolio management

According to a recent survey reported by the Yale School of Management

(Goetzmann and Dhar (2005)), there is strong evidence that the majority of some 173

surveyed leading institutional investors and fund managers regard the Modern Portfolio

Theory (Markowitz (1952)) as the basic analytical framework for making asset allocation

decisions about mixed-asset investment portfolios that include real estate. Although many

investors perceive real estate as offering potential diversification benefits, they are most

concerned with the accuracy and reliability of the statistical estimates of real estate return and

risk. In particular, the risk due to illiquidity (or lack of liquidity) is reported as the leading

risk factor that affects real estate allocation decisions. Such concerns are justified because, in

the current practice of applying the Modern Portfolio Theory (MPT) via mean-variance

optimization to mixed-asset portfolio analysis, the illiquidity risk is not quantified and

incorporated into the risk measurement of real estate. As the result, real estate appears to

exhibit significantly higher risk-adjusted returns than other assets, such as stocks and bonds.

This is a widely documented observation known as the "real estate risk premium puzzle.” It 
is the direct cause of another equally famous puzzle known as the "real estate allocation puzzle," which refers to the large discrepancy between the academic proposition of $15 \%$ to $40 \%$ real estate allocation in mixed-asset portfolios and the reality that leading institutional portfolios typically contain only about $3 \%$ to $5 \%$ in real estate. ${ }^{1}$ The key to the reconciliation of such discrepancy is to find out if there is indeed a "real estate risk premium puzzle". This is critical to the application of MPT because the mean-variance optimization process has proven so sensitive to the risk and return inputs that reasonable asset allocation cannot be obtained without the performances of competing asset classes being measured properly and fairly. Our objective for this paper is to provide a solution to the "real estate risk premium puzzle”.

\section{The Real Estate Risk Premium Puzzle}

It has been extensively documented in the real estate literature that private real estate equity (as exemplified by the NCREIF property indices ${ }^{2}$ ) exhibits much higher risk-adjusted returns than other asset classes such as common stocks and bonds. The phenomenon is so widely reported that it can be found in nearly every study published in the last twenty years that investigates the role of real estate in the construction of optimal mixed-asset portfolios. Although the body of the literature is too large to be reviewed here in detail, it suffices to say that the findings are more than anecdotal, for the same evidence is presented by many studies using different data sources over different time periods. And such evidence can be readily

\footnotetext{
${ }^{1}$ The Yale report echoes an earlier survey by Pension \& Investments (2002), which reported that the top 200 defined-benefit pension funds had only about $3 \%$ of their total assets in private real estate equities.

${ }^{2}$ The National Council of Real Estate Investment Fiduciaries (NCREIF) maintains and publishes the NCREIF Property Index, which has been widely accepted as the performance benchmark for commercial real estate in the U.S. For more information, visit www.ncreif.com.
} 
reproduced by simple computations. For example, by collecting quarterly return indices, we can easily produce a comparison of the risk and returns of various assets as shown in Table 1.

Table 1. Quarterly Returns and Risks of Asset Classes (1978Q1-2007Q2)

\begin{tabular}{rccc}
\hline \hline & Mean & Stdev & Sharpe ratio \\
S\&P 500 & $3.26 \%$ & $9.99 \%$ & 0.27 \\
NASDAQ & $2.66 \%$ & $7.60 \%$ & 0.27 \\
Dow Jones Industrial & $2.68 \%$ & $7.04 \%$ & 0.29 \\
Private Equity (NCREIF) & $2.48 \%$ & $1.70 \%$ & 1.11 \\
Industrial & $2.57 \%$ & $1.65 \%$ & 1.20 \\
Office & $2.33 \%$ & $2.58 \%$ & 0.67 \\
Retail & $2.52 \%$ & $1.65 \%$ & 1.17 \\
Apartment & $2.88 \%$ & $1.62 \%$ & 1.41 \\
OHFEO Official Index & $1.35 \%$ & $0.94 \%$ & 0.80 \\
OHFEO Purchase-only & $1.31 \%$ & $0.89 \%$ & 0.81 \\
\hline
\end{tabular}

Note: All return series are based on quarterly data from 1978Q1 through 2007Q2, except for the OFHEO (Office of Federal Housing Enterprise Oversight) Purchase-only index, which begins in 1991Q1. The table shows that all categories of private real estate equity exhibit significantly higher risk-adjusted returns than stocks. The risk-free rate is obtained from Ken French's website. For the period analyzed, the average quarterly risk-free rate is $0.59 \%$.

As shown above, the private equity real estate indices (NCREIF overall and the sector indices) all exhibit average returns that are slightly lower, but fairly comparable to common stocks (particularly to the NASDAQ and Dow Jones Industrial indices), but the return volatilities of real estate are only a small fraction of that of stocks. As a result, real estate exhibits much higher Sharp Ratios than do common stocks. This is the phenomenon known as the "real estate risk premium puzzle."

A widely-held opinion in the real estate literature is that the low return volatility of the NCREIF index is caused by so-called "appraisal smoothing." Ibbotson and Siegel (1984) 
is perhaps among the first to use the term "smoothing" to describe the notion that appraisers' opinions of value are inherently based on prior market information of various ages. Relying on prior information may cause appraisers to adjust property value estimates insufficiently to reflect the "true" changes in market condition. As a result, the appraisal-based value index appears less volatile (or more smoothed) than if the index were transaction-based. Because the NCREIF index is based on quarterly appraised values of properties owned by the NCREIF member companies, it is likely to suffer the smoothing bias and exhibits less volatility, thus producing upwardly biased Sharp Ratios for real estate.

Although conceptually appealing, empirical evidence of “appraisal smoothing” has not been conclusive. On one hand, many studies that set out to measure the magnitude of appraisal smoothing have failed to find significant appraisal errors. For example, Cole et al. (1986) and Dotzour (1988) report no statistically significant difference between appraised values and transaction prices for commercial and residential properties. On the other hand, a number of studies over the years have identified appraisal errors in the NCREIF database. ${ }^{3}$ However, the magnitudes of the appraisal errors are generally found to be rather moderate. For example, Geltner and Goetzman (2000) exclude appraisal data in the NCREIF property sample and construct a transaction-based NCREIF index from 1978 to 1998 . They find that the average quarterly return for their transaction-based NCREIF index is $2.3 \%$ with a standard deviation of $2.13 \%$, which is only slightly different from the standard deviation of the appraisal-based index (2.28\% return with $1.83 \%$ standard deviation). This finding suggests that the impact of appraisal smoothing may not be very significant in underestimating the NCREIF index volatility.

\footnotetext{
${ }^{3}$ See Wang (2006) for a summary of the literature.
} 
Similar observations can be made from the two OFHEO indices in Table 1. The OFHEO Official Index is widely regarded as the benchmark for the U.S. housing market. It is constructed based on a mix of transaction amounts and appraisal values (similar to the NCREIF index). The portions of the appraisal data varies over the years and can be as high as $60 \%$. So the volatility of this index is expected to exhibit some appraisal smoothing. On the other hand, the OFHEO Purchase-only Index does not contain appraisal data. As can be seen in Table 1, the two indices show nearly identical Sharp ratios, suggesting that the presence of appraisal influence in the official index is negligible. While extensive research on the "smoothing" issue is likely to continue, it is safe to say that the real estate risk premium (as shown in Table 1) is simply too large to be dismissed as solely an artifact of smoothing bias.

In this paper, we show that the cause for the seemingly superior performance of real estate lies in how real estate risk is measured. We show that the conventional risk measure (standard deviation of historic returns) has some fundamental problems in capturing the true risk of real estate. The solution to the "real estate risk premium puzzle" lies in the solutions of these problems.

\section{The Problem with the Current Valuation of Illiquid Asset Performance}

Fair comparisons of investment performance should be based on assets' risk-adjusted returns. The well-known Sharpe Ratio is perhaps the most common measure for such purpose. According to Sharpe (1966), the ratio is defined as 


$$
S=\frac{E(R)-r_{f}}{\sqrt{\operatorname{Var}(R)}}
$$

where $E(R)$ is the expected periodic return of an asset, $\operatorname{Var}(R)$ is the variance of the return, and $r_{f}$ is the corresponding expected periodic risk-free rate.

Now assume an asset is to be held for $\tau$ periods (years, months, quarters, etc.) and is expected to realize a total return and variance of $\bar{r}_{\tau}$ and $\sigma_{\tau}^{2}$, respectively. Then

$$
\begin{aligned}
& E(R)=\bar{r}_{\tau} / \tau \\
& \operatorname{Var}(R)=\sigma_{\tau}^{2} / \tau
\end{aligned}
$$

Substituting Equation (2) into Equation (1) yields

$$
S=\frac{\bar{r}_{\tau} / \tau-r_{f}}{\sqrt{\sigma_{\tau}^{2} / \tau}}
$$

Equation (3) can be used to compare the risk-adjusted returns of assets for different holding periods. However, in the world of an efficient market, it is widely accepted that the prices of security assets can be reasonably assumed to follow the so-called geometric Brownian motion, that is, security returns are independent and identically-distributed (i.i.d.) over time. The i.i.d. assumption implies

$$
\begin{aligned}
& \bar{r}_{\tau}=\tau u \\
& \sigma_{\tau}^{2}=\tau \sigma^{2}
\end{aligned}
$$

where $u$ and $\sigma$ are the expected return and volatility, respectively, of investing in an asset for a single-period.

\footnotetext{
${ }^{4}$ In recognition of a variable risk-free rate, Sharpe (1994) provides a modified version of the ratio as $S=\frac{E\left(R-r_{f}\right)}{\sqrt{\operatorname{Var}\left(R-r_{f}\right)}}$. The new version improves empirical estimation of the ratio but preserves all the theoretical essence of the original version.
} 
Substituting Equation (4) into Equation (3) yields the widely used textbook format of Sharpe ratio:

$$
S=\frac{u-r_{f}}{\sigma}
$$

Clearly, the implicit assumption for the Sharpe ratio expressed in Equation (5) is that security asset returns over time are i.i.d. This has a powerful implication because, under this assumption, the Sharpe ratio for a multi-period investment can be expressed in terms of single-period return and risk. The studies by Samuelson (1969), Merton (1969), and Fama (1970) further show that, under this assumption, an investor's utility maximization over multiple periods are essentially indistinguishable from that over a single-period. In other words, asset valuation and portfolio selection need only to be based on single-period return and risk with no regard to expected holding time. This is the basis for applying renowned single-period models such as the Modern Portfolio Theory (Markowitz (1952)) and the CAPM (Sharpe (1964) and Lintner (1965)) to multi-period investment decisions. To extend the applications of these theories, as well as the Sharpe ratio in Equation (5), to thinly-traded assets such as real estate, one must at least answer the obvious question: Can returns of real estate (or any other thinly-traded assets) be reasonably assumed to be independent and identically-distributed? ${ }^{5}$

In the field of real estate research, this question has been answered by many studies. For example, Case and Shiller (1989) tests the efficiency of the U.S. housing market and find that housing prices are serially correlated and partially predictable. England et al. (1999) analyzes a large sample of Swedish housing prices and rejected the random walk hypothesis

\footnotetext{
${ }^{5}$ In fact, this is also a legitimate question even for the stock market, in light of the findings by Keim and Stambaugh (1986), Campbell (1987), Fama and French (1988, 1989), and Campbell (1991), among others. These studies have shown that stock returns exhibit various degree of predictability, as opposed to complete random walk.
} 
in favor of a first order serial correlation. Leung (2007) constructs an equilibrium model and finds that the auto-correlations and cross-asset correlations of the equilibrium prices and return of assets (housing and equity) will be non-zero. In the commercial real estate market, Young and Graff (1995) and Young (2008) find that the benchmark NCREIF property index returns are neither normal nor stable over time. Overall, it suffices to say that these empirical studies have long established that the real estate market is not efficient and that the real estate price (or return), whether residential or commercial, exhibits strong serial persistence and predictability. That is, they are not i.i.d. The non-i.i.d. reality implies that utility maximization of a multi-period investment may be different from that of a single-period investment, and the results of applying single-period asset pricing models may not hold for a multi-period investment.

But if the returns on a real estate asset are not i.i.d., then what are they? A recent study by Lin and Liu (2008) provides an answer to this question. The study first takes a theoretical approach to model the real estate transaction process and price distribution over time, and derives a different risk structure for real estate as $\sigma_{\tau}^{2}=\tau^{2} \sigma^{2}$ or $\sigma_{\tau}=\tau \sigma$, as opposed to the i.i.d. assumption in Equation (4). The authors then empirically examine the risk structure of the OFHEO residential index and find that the residential property data indeed exhibit a risk structure that is far different from the Brownian motion but is reasonably close to their alternative risk structure. This finding raises a broader question: can the similar risk structure be found in commercial real estate, or any other illiquid asset classes? In the next section, we examine this issue with the NCREIF data. 


\section{The Real Estate Return Distribution over Holding Period}

In this section, we first verify the finding of Lin and Liu (2008) with the NCREIF Property Index. We show that their finding, though much more reasonable than the i.i.d. assumption, is an approximation nonetheless. We demonstrate the use of a simple regression to empirically obtain the risk structure without relying on some kind of simplifying assumptions.

Using quarterly NCREIF Property Index from 1978Q1 to 2007Q2 ${ }^{6}$ we first compute return indexes for various holding periods ranging from one quarter to 36 quarters (9 years). We then compute the standard deviation for each return series, which we denote with $\sigma_{\tau}$, where $\tau=1,2,3, \ldots 36$, and $\sigma_{\tau}$ is the total volatility for holding-period $\tau$. We then repeat the same computation for the quarterly S\&P 500 Index. For easy comparison, we standardize $\sigma_{\tau}$ by computing $\sigma_{\tau} / \sigma_{1}$, so that the risk of a single-quarter holding period is scaled down to 1, and we plot the standardized numbers in Figure 1. Then, given the price risk for a singlequarter holding period being 1 , we also plot the multi-period risk increasing along the path of geometric Brownian motion ( $\sigma_{\tau}=\sqrt{\tau} \sigma$, where $\sigma=\sigma_{1}$ representing the risk of investing for a single-period ${ }^{7}$ ) as well as the alternative risk structure derived by Lin and Liu (2008).

\footnotetext{
${ }^{6}$ The National Council of Real Estate Investment Fiduciaries (NCREIF) maintains and publishes the NCREIF Property Index, which has been widely accepted as the performance benchmark for commercial real estate in the U.S. For more information, visit www.ncreif.com.

${ }^{7}$ To be consistent in notation, we will subsequently use $\sigma$ instead of $\sigma_{1}$ to denote the risk of investing for a single-period.
} 
Figure 1. Comparison of the Risk Structure of NCREIF vs. S\&P500

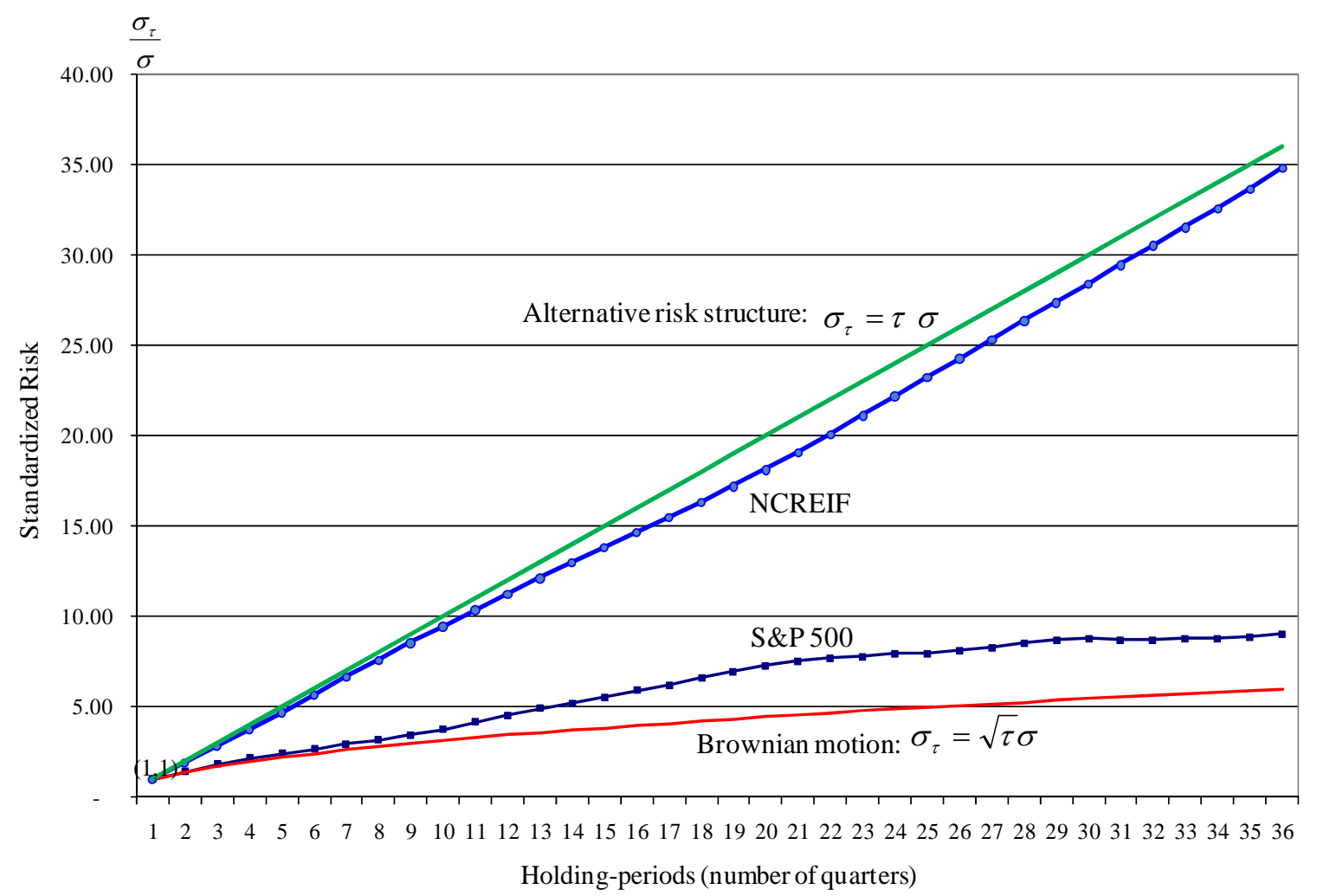

Two observations are immediately clear from Figure 1: first, while the price risk structure of the S\&P 500 is reasonably close to the Brownian motion, the NCREIF is far away from that path. Instead, the NCREIF line is rather much closer to the alternative risk structure proposed by Lin and Liu (2008). This pattern is quite similar to the empirical findings of Lin and Liu (2008) which uses the OFHEO residential property data. Second, the standardized risk of NCREIF closely resembles a straight-line. This feature enables us to empirically model its risk structure, rather than relying on the alternative risk structure, which appears to overestimate the NCREIF risk at longer holding periods. Although Figure 1 provides only 36 quarters of calculation and, given that empirical studies have shown that 
institutional investors typically hold commercial properties for only five to eight years, ${ }^{8}$ modeling the risk structure up to 36 quarters (nine years) is reasonably sufficient. Certainly, provided with sufficient data, investors can extend the range of holding period to any length they prefer.

A likely question to occur at this point may be that, because the NCREIF index is an appraisal-based return series, the risk structure in Figure 1 does not reflect the "true" behavior of NCREIF returns, rather it is just the temporal lag bias caused by appraisal smoothing. For lack of a reliable purchase-transaction-based commercial real estate index, we turn to the residential data to see the effect of appraisal smoothing. We gather two nonappraisal real estate indices - the OFHEO Purchase-only Index and the S\&P/Case-Shiller® Home Price Indices - as well as the OFHEO Official appraisal-based Home Price Index and replicate Figure 1 as the following Figure $1 \mathrm{~A}$.

Figure 1A. Real Estate Risk Structure in the Residential Market

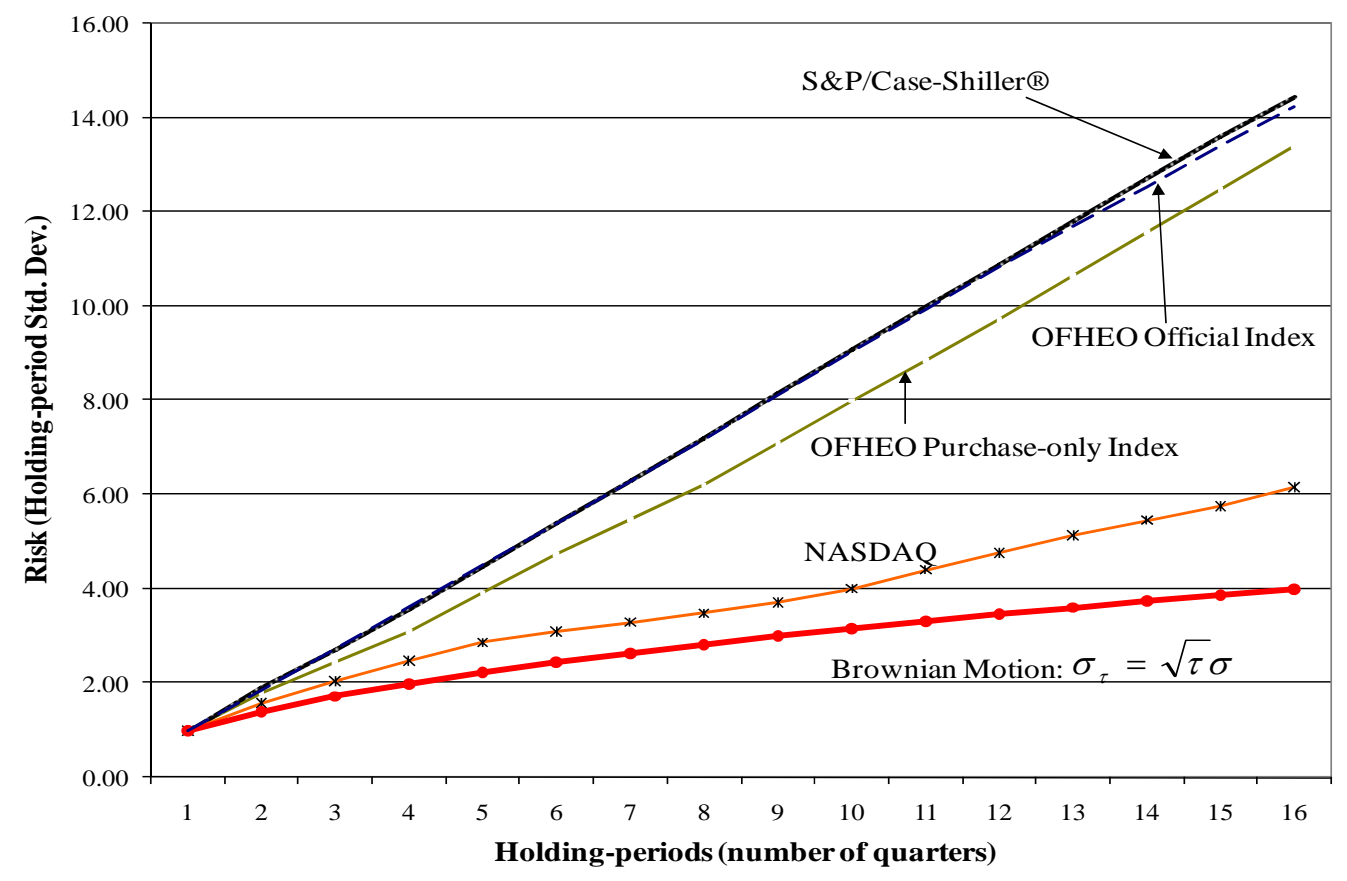

\footnotetext{
${ }^{8}$ See for example Gau and Wang (1994).
} 
Figure 1A shows nearly identical patterns to those in Figure 1-the NASDAQ index is close to Brownian motion but the two real estate indices lie far above it. Notice that the OFHEO Official Index (which includes appraisals) lies only slightly above the purchase-only index, and is almost identical to the S\&P/Case-Shiller ${ }^{\circledR}$ Index, which is in fact transactionbased. The closeness between the appraisal-based OFHEO Official Index and the two transaction-based indices indicates that, if their differences are indeed caused by the appraisal smoothing effect, such effect is likely to be small. Although this evidence in Figure 1A is from the residential market, given the similar micro-market structure and transaction process in the residential and commercial markets (i.e. prices are formed through sequential search and a random match of buyers and sellers), it is reasonable to expect that the appraisal bias is no more significant in the NCREIF index than in these residential indices, and that the noni.i.d. pattern is not unique to the residential market. In other words, the non-i.i.d. risk structure of the NCREIF Index displayed in Figure 1 cannot easily be dismissed as a result of appraisal bias alone.

Now we return to model the NCREIF line in Figure 1. Note that the line passes through the point $(1,1)$. Thus we have

$$
\frac{\sigma_{\tau}}{\sigma}=1+\beta^{T}(\tau-1)
$$

where $\tau$ is the holding-period, and $\beta^{T}$ is the slope of the NCREIF line, which can easily be obtained through the following simple regression with $\tau$ as the independent variable:

$$
\frac{\sigma_{\tau}}{\sigma}-1=\beta^{T}(\tau-1)+\varepsilon
$$

Note that this regression has no intercept, and $\varepsilon$ reflects the random error. Once the regression coefficient $\beta^{T}$ is obtained, we can estimate 


$$
\sigma_{\tau}=\sigma+\beta^{T}(\tau-1) \sigma
$$

The magnitude of $\beta^{T}$ indicates the degree to which an asset's risk increases with holding period. As $\beta^{T}$ increases, $\sigma_{\tau}$ grows more quickly as holding-period increases. Replacing the risk structure in Equation (4) with the empirical estimate of Equation (8) yields a non-i.i.d. description of the NCREIF return distribution.

$$
\begin{aligned}
& \bar{r}_{\tau}=\tau u \\
& \sigma_{\tau}^{2}=\left[\sigma+\beta^{T}(\tau-1) \sigma\right]^{2}
\end{aligned}
$$

Note that the model for $\sigma_{\tau}^{2}$ is not based on a particular distribution, but rather an empirical estimation, which is in fact more accurate than the Brownian motion or the Lin-Liu alternative in reflecting the real estate's actual return volatilities for various holding periods. We keep $\bar{r}_{\tau}$ unchanged as it is in Equation (4), since we find that the NCREIF periodic returns are about the same across different holding periods. The expected holding period return $\bar{r}_{\tau}=\tau u$ is thus reasonably accurate.

In addition to the NCREIF data, we also collect the quarterly return index of NCREIF sub-indices for four major property types - industrial, office, retail and apartments for the same period, 1978Q1 to 2007Q2. With each of these sub-indices, we repeat the computation on the NCREIF overall index that produced Figure 1, and conduct the regression in Equation (7). The results are summarized in Table 2. 
Table 2. Summary of NCREIF Data and the $\beta^{T}$ Estimates

\begin{tabular}{lccccccc}
\hline & & & \multicolumn{5}{c}{$\beta^{T}$ Estimation } \\
\cline { 5 - 8 } & Mean $(u)$ & St.Dev. $(\sigma)$ & $\beta^{T}$ & $t$-stat & Sig. & Adj. -sqr \\
\hline NCREIF Overall & 2.48 & 1.70 & 0.94 & 278.42 & 0.00 & 0.97 \\
Industrial & 2.57 & 1.65 & 0.96 & 294.92 & 0.00 & 0.97 \\
Office & 2.33 & 2.58 & 0.82 & 250.12 & 0.00 & 0.97 \\
Retail & 2.52 & 1.65 & 0.93 & 243.68 & 0.00 & 0.97 \\
Apartment & 2.88 & 1.62 & 0.91 & 259.21 & 0.00 & 0.97 \\
\hline
\end{tabular}

The adjusted $R^{2}$ of 0.97 in Table 2 indicates that all five data series exhibit strong linear patterns. From equation (8), the estimated holding-period volatility for asset $i$ can be obtained as

$$
\hat{\sigma}_{\tau, i}=\hat{\sigma}_{i}+\beta_{i}^{T}(\tau-1) \hat{\sigma}_{i}
$$

Equation (8') indicates that the risk of holding real estate for certain periods is affected by two variables - the single-period risk and the slope of $\beta^{T}$. In essence, $\beta^{T}$ captures the effect of holding-period on real estate risk. Such an effect is ignored in traditional practice where investment risk is estimated only by a single-period risk $\hat{\sigma}_{i}$. Given that $\beta^{T}$ is likely to be asset-specific, two assets with same single-period risk may have very different holding-period risk (or average risk per period) over multi-period investment, even more so when they are held for different periods of time.

Keep in mind, however, that $\sigma_{\tau}^{2}$ captures only the risk due to price volatility, which is based on ex post observed data or after-the-fact basis. In reality, however, when a real estate asset is placed on the market, the time when the property is sold is not known in ex ante. As a result, the investor faces two risks in the real estate market - the price volatility and the 
uncertain time-on-market. These two risks must be integrated into a single risk metric to capture the overall risk of real estate. We accomplish this in the next section.

\section{Integrating Illiquidity Risk into Real Estate Valuation}

We begin by illustrating the real estate transaction process and highlighting the unique feature of the thinly-traded real estate asset. Then we present a formal derivation of an integrated risk metric that captures both price risk and illiquidity risk. A by-product of this development is a modified Sharpe ratio for real estate, which will be used to re-examine the long-standing “real estate risk premium puzzle”.

\subsection{The Real Estate Transaction Process}

Figure 2 is a simple illustration of the real estate transaction process. Suppose that an investor purchases a property at time 0 , holds it for time $t$ and then places it on the market for sale. Since selling immediately at time $t$ is often not optimal (see Lippman and McCall (1986)), from the ex ante perspective, the investor faces two sources of risk at the time of sale: the random time-on-market (TOM) and the random future selling price or return (given TOM). Therefore, at the time of sale, the investor's return ex ante of the sale, $\tilde{r}_{t+T O M}$, can be regarded as a function of these two stochastic variables. Upon successful sale of the asset after a period of time-on-market, TOM, the investor receives a total return of $\tilde{r}_{t+\text { Tом }} \mid$ TOM , which is the realized and observable return ex post of the sale. Note that both TOM and $\tilde{r}_{t+T O M} \mid T O M$ are stochastic in nature. 


\section{Figure 2 The Real Estate Transaction Process}

Two risks at time of decision:

- random selling price

- random time-on-market.

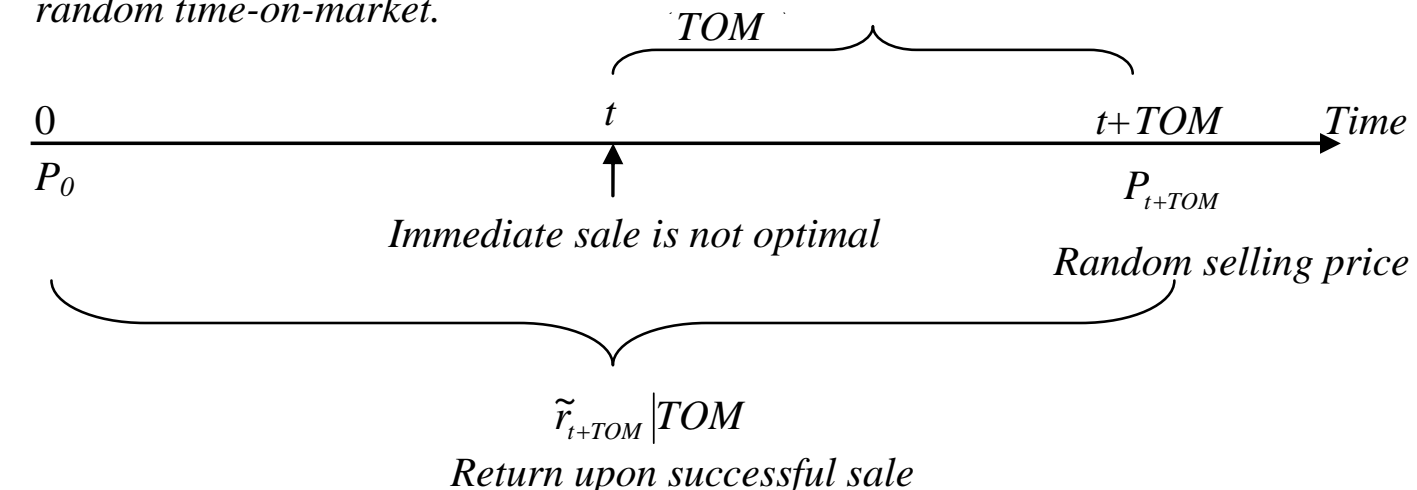

The above illustration highlights the unique feature of the real estate transaction process. Unlike financial assets, which can be sold instantly at point $t$, real estate cannot be sold immediately. Instead, the investor must take time to search for potential buyers. Both the final price and the timing of the price are uncertain at initial market time, and the two variables are closely related. ${ }^{9}$ Other things being equal, identical properties can realize very different selling prices with different time-on-market. In other words, the realized (observable) selling price is, in part, the outcome of the investor bearing the risk due to the uncertain time-on-market (as well as the associated costs). In addition, the uncertain time-onmarket is set by the investor's optimal stopping rule according to his objective, market condition, and personal constraints. ${ }^{10}$

\footnotetext{
${ }^{9}$ See, for example, Cheng, Lin, and Liu (2008) for detailed literature review.

${ }^{10}$ Lippman and McCall (1986) provide a formal discussion on how the uncertain time-on-market is determined.
} 


\subsection{The ex ante Real Estate Risk}

Given the fact that real estate typically cannot be sold immediately, the holding period of a property with observable transaction price actually consists of two parts - the holding time from purchase to listing the property for sale $(t)$, and the marketing time necessary to reach a contract with a buyer. ${ }^{11}$ Therefore, the total holding time until sale is $\tau=t+T O M$, Equation (9) can thus be rewritten as:

$$
\begin{aligned}
\bar{r}_{t+\text { TOM }} & =(t+\text { TOM }) u \\
\sigma_{t+T O M}^{2} & =\left[\sigma+\beta^{T}(t+T O M-1) \sigma\right]^{2}
\end{aligned}
$$

Therefore, the holding-period return at time of sale $(t+T O M)$ follows the distribution with the mean and variance expressed in Equation (10). That is,

$$
\tilde{r}_{t+T O M} \sim\left((t+T O M) u,\left[\sigma+\beta^{T}(t+T O M-1) \sigma\right]^{2}\right)
$$

As discussed earlier, at the time the property is placed on the market for sale the investor also faces uncertain time-on-market (TOM). That is, both TOM and the total return upon sale $\left(\tilde{r}_{t+T O M} \mid T O M\right)$ are stochastic variables. Without specifying a particular distribution for TOM, we denote its mean and variance as $t_{\text {Tом }}$ and $\sigma_{\text {TOM }}^{2}$, respectively. Both $t_{\text {TOM }}$ and $\sigma_{\text {TOM }}^{2}$ essentially capture the degree of real estate illiquidity.

By applying the conditional variance formula for any two stochastic variables ${ }^{12}$, the variance of real estate returns can be computed as

$$
\operatorname{Var}^{\text {ex-ante }}\left(\tilde{r}_{t+T O M}\right)=\operatorname{Var}\left(E\left[\tilde{r}_{t+T O M} \mid T O M\right]\right)+E\left[\operatorname{Var}\left(\tilde{r}_{t+T O M} \mid T O M\right)\right]
$$

\footnotetext{
${ }^{11}$ Typically there is some time lag between when the sales price is agreed upon and when the money changes hands, during which time the seller still holds the property. We ignore this time period because we assume the observed transaction price (or return) reflects the asset's value at the time of contracting, and the seller's return is not affected by this time.

${ }^{12}$ For the conditional variance formula, see page 379 of Ross (2002).
} 
Here we use the term ex ante variance ( $\operatorname{Var}^{\text {ex-ante }}$ ) to emphasize the fact that, at the initial market time, the investor is uncertain about the price and timing of the realized sale. In other words, the ex ante risk is a forward-looking risk measure that is unconditional upon a successful sale. In contrast, the conventional risk measure is based solely on the prices of the realized sales and ignores the uncertainty of TOM.

From Equation (11) we have

$$
E\left[\tilde{r}_{t+T O M} \mid T O M\right]=\bar{r}_{t+T O M}=(t+T O M) u
$$

and

$$
\operatorname{Var}\left(\tilde{r}_{t+T O M} \mid T O M\right)=\left[\sigma+\beta^{T}(t+T O M-1) \sigma\right]^{2} .
$$

We can thus rewrite Equation (12) as

$$
\operatorname{Var}^{\text {ex-ante }}\left(\tilde{r}_{t+T O M}\right)=\operatorname{Var}([t+T O M] u)+E\left(\left[\sigma+\beta^{T}(t+T O M-1) \sigma\right]^{2}\right) .
$$

Given that $E[T O M]=t_{\text {Tом }}$ and $\operatorname{Var}(T O M)=\sigma_{\text {TOM }}^{2}$, simplifying Equation (15) yields

$$
\begin{aligned}
\operatorname{Var}^{\text {ex-ante }}\left(\tilde{r}_{t+T O M}\right)= & \left(t+t_{\text {TOM }}\right)^{2}\left(\beta^{T}\right)^{2} \sigma^{2}+\left(u^{2}+\left(\beta^{T}\right)^{2} \sigma^{2}\right) \sigma_{\text {TOM }}^{2}+ \\
& 2\left(t+t_{\text {TOM }}\right) \sigma^{2} \beta^{T}\left(1-\beta^{T}\right)+\sigma^{2}\left(1-\beta^{T}\right)^{2}
\end{aligned}
$$

Therefore, the average periodic ex ante risk for the expected holding period until sale $\left(t+t_{\text {TOM }}\right)$ can be expressed as

$$
\sigma^{\text {ex-ante }}=\sqrt{\left(t+t_{\text {TOM }}\right)\left(\beta^{T}\right)^{2} \sigma^{2}+2 \sigma^{2} \beta^{T}\left(1-\beta^{T}\right)+\frac{\left(u^{2}+\left(\beta^{T}\right)^{2} \sigma^{2}\right) \sigma_{\text {TOM }}^{2}+\sigma^{2}\left(1-\beta^{T}\right)^{2}}{\left(t+t_{\text {TOM }}\right)}} .
$$

Equation (17) is a unified risk measure that integrates both price risk and marketingperiod risk of the real estate asset. Such a unified risk metric reveals that the valuation of the thinly traded real estate asset is much more complex than the conventional valuation of the thickly traded asset. In particular, Equation (17) suggests that the average periodic risk of 
thinly traded assets is determined by many factors, such as illiquidity ( $t_{\text {Tом }}, \sigma_{\text {TOM }}^{2}$ ), investor's holding period $(t)$, single-period return distribution $\left(u, \sigma^{2}\right)$, and the slope of the risk growth $\left(\beta^{T}\right)$. However, the conventional risk estimate of the thickly traded asset is simply $\sigma^{2}$ for all holding periods.

Four points are worth noting:

First, Equation (17) shows that the uncertainty of TOM $\left(\sigma_{\text {TOM }}^{2}\right)$ and the mere fact of having to wait the extra holding time to sell ( $t_{\text {TOM }}$ ) lead to higher periodic ex ante risk. In other words, both the first and second moments of TOM ( $t_{\text {том }}$ and $\sigma_{\text {TOM }}^{2}$ ) matter to the overall real estate risk. This is significantly different from Lippman and McCall (1986) which suggests the first moment (expected TOM) is a sufficient measure for illiquidity.

Second, the current practice of using the conventional risk estimate, which is directly borrowed from finance theory, not only fails to account for illiquidity risk but also fails to consider the non-i.i.d. nature of real estate assets. As a result, it underestimates real estate risk.

Third, given the results in Table 2 , if we approximate $\beta^{T} \approx 1$, Equation (17) can be simplified as

$$
\sigma^{e x-a n t e} \approx \sqrt{\left(t+t_{\text {TOM }}\right)^{2} \sigma^{2}+\frac{\left(u^{2}+\sigma^{2}\right) \sigma_{T O M}^{2}}{\left(t+t_{\text {TOM }}\right)}}
$$

This reveals a "trade-off" effect of holding-period on the ex ante risk. If the holding time $\left(t+t_{\text {TOM }}\right)$ is relatively short, the uncertainty of time-on-market $\left(\sigma_{\text {TOM }}^{2}\right)$ will affect the ex ante risk more. While the effect of $\sigma_{\text {TOM }}^{2}$ can be mitigated by increasing the holding-period, the trade-off is that the single-period price risk $\left(\sigma^{2}\right)$ will be magnified by the longer holding 
period. So the ex ante risk is not necessarily reduced by holding the property longer. In other words, although illiquidity risk may not be an issue when the holding period is sufficiently long, investors should be aware of the downside of holding properties for too long, that is, ex ante risk (per period) increases with the holding period. This finding is consistent with a recent discovery by Collett et al (2003) that private real estate looks less attractive once more realistic and longer time horizons are considered.

Finally, it should be noted that, Equation (17) indicates that the specific distribution of TOM is not necessarily required to be known so long as the mean and standard deviation of the TOM can be estimated.

\subsection{A Modified Sharpe Ratio for Real Estate}

For the ex ante expected return, we first calculate the expected ex post return, conditional upon selling at point (TOM), and then use the Law of Iterated Expectations:

$$
\begin{aligned}
E^{\text {ex-ante }}\left[\tilde{r}_{t+\text { TOM }}\right] & =E\left[E\left[\tilde{r}_{t+\text { TOM }} \mid T O M\right]\right] \\
& =E[(t+T O M) u] \\
& =\left(t+t_{\text {TOM }}\right) u
\end{aligned}
$$

Hence, the average periodic ex ante return is ${ }^{13}$

$$
u^{\text {ex-ante }}=E^{\text {ex-ante }}\left[\tilde{r}_{t+T O M}\right] /\left(t+t_{\text {ТОм }}\right)=u \text {. }
$$

From Equations (17) and (19), we can conclude that the real estate Sharpe ratio for holding period $t+t_{\text {TOM }}$ is

\footnotetext{
${ }^{13}$ The ex-ante return is the same as the return estimate from traditional approaches that ignore illiquidity risk. However, this result holds only when the ex post return linearly increases in holding time, as assumed. If the market faces a downturn (or upturn), this assumption is likely to be violated. We can show that the average periodic ex ante return will be less (greater) than the return estimated from the traditional approach.
} 


$$
S_{R E}=\frac{u-r_{f}}{\sqrt{\left(t+t_{\text {TOM }}\right)\left(\beta^{T}\right)^{2} \sigma^{2}+2 \sigma^{2} \beta^{T}\left(1-\beta^{T}\right)+\frac{\left(u^{2}+\left(\beta^{T}\right)^{2} \sigma^{2}\right) \sigma_{\text {TOM }}^{2}+\sigma^{2}\left(1-\beta^{T}\right)^{2}}{\left(t+t_{\text {TOM }}\right)}}}
$$

The denominator of Equation (20) is Equation (17), which reveals the complex nature of the real estate risk. This modified Sharpe ratio overcomes the two problems with applying the classical Sharpe ratio (Equation (5)) to the thinly-traded real estate asset, namely, the $S_{R E}$ does not rely on the i.i.d. assumption, and it captures the illiquidity risk that is not priced by the traditional finance theory. Using this new Sharpe ratio for real estate, we can now reexamine the long-standing real estate risk premium puzzle.

\section{Solution to the Real Estate Risk Premium Puzzle}

In this section, we apply empirical data to the real estate Sharpe ratio in Equation (20) to re-examine the real estate risk premium puzzle presented in Table $1 .{ }^{14}$ We use the same NCREIF index data that were used to produce Table 1 . The dataset includes quarterly return series of NCREIF overall and four major types of commercial properties—apartments, industrial, office, and retail. The time span of the data is 1978Q1 to 2007Q2. In order to estimate Equation (20), we need to know the following quantities:

(1) The periodic return and risk of NCREIF indices, $u$ and $\sigma$ : These are as displayed in Table 1.

(2) The risk growth factor $\beta^{T}$ for each data series: This has been done in Table 2.

\footnotetext{
${ }^{14}$ The Sharpe ratios in Table 1 are computed using Equation (5) with quarterly data. It should be noted that, if the "period" is defined as annual as opposed to quarterly, all Sharpe ratios would be twice as large (see Appendix A), but the "risk premium puzzle" still exists.
} 
(3) The distribution of the time-on-market, i.e., $t_{\text {Tом }}$ and $\sigma_{\text {TOM }}^{2}$ : By using UK

commercial property transactions, Bond et al. (2007) investigate a number of assumptions about the distribution of times to sale, such as the normal, the negative exponential, gamma, and Weibull distributions, and finds that the negative exponential density function explains the data better than the other assumptions. While such a finding requires further verification from the U.S. and other markets before it is generalized, it should be noted that our model derivation leading up to Equation (20) does not require a specific distribution of TOM, but only that $t_{\text {TOM }}$ and $\sigma_{\text {TOM }}^{2}$ need to be estimated. For the current study, we tentatively accept the negative exponential distribution, which has a convenient mathematical property: Its variance is equal to the square of its mean. Therefore, the variance of the time-on-market (TOM) is equal to the square of the expected TOM, i.e., $\sigma_{\text {TOM }}^{2}=t_{\text {TOM }}^{2}{ }^{15}$ Thus, Equation (20) can be rewritten as

$$
S_{R E}=\frac{u-r_{f}}{\sqrt{\left(t+t_{\text {TOM }}\right)\left(\beta^{T}\right)^{2} \sigma^{2}+2 \sigma^{2} \beta^{T}\left(1-\beta^{T}\right)+\frac{\left(u^{2}+\left(\beta^{T}\right)^{2} \sigma^{2}\right) t_{T O M}^{2}+\sigma^{2}\left(1-\beta^{T}\right)^{2}}{\left(t+t_{T O M}\right)}}}
$$

We assume a range of time-on-market ( $t_{\text {TOM }}$ ) from four to 14 months. Based on the National Association of Realtors, the average TOM for the US residential market during the period from 1989 to 2006 is about 6 months. Given the fact that average marketing periods in commercial markets are at least as long as those in residential markets, we choose $t_{\text {том }}$ from four to 14 months.

(4) Real estate holding periods (t): Since holding periods can vary greatly among investors, we will simply consider a range of holding periods in our analysis. Gau and Wang

\footnotetext{
15 See pages 211-212, Ross (2002).
} 
(1994) analyze over 1,000 Canadian commercial real estate transactions and find average holding periods from five to eight years, depending on property type. Collett et al. (2003) study the UK property market and find that the median holding period of UK properties generally fell from around 12 years in the early 1980s to less than eight in the late 1990s. Through a sample of small apartment buildings over the period from 1970 to 1990 in the city of San Diego, Brown and Geurts (2005) find that the average holding period for these properties is around five years. In light of these findings, it is reasonable to consider a range of real estate holding period over three to eight years.

With all the parameters in hand, we can estimate the real estate Sharpe Ratios using Equation (21), and present the results in Table 3. The shaded area in Table 3 corresponds to the more typical real estate holding period of five to eight years. Under reasonable scenarios of time-on-market and investor's expected holding period, the "real estate risk premium puzzle” largely disappears and the real estate Sharpe Ratios are now much in-line with that of stocks in Table 1.

Generally speaking, the Sharpe Ratios in Table 3 decline as holding-period and/or TOM increases. However, the ranges of the Sharpe Ratios are fairly narrow despite the wide range of assumed TOM and holding period. 
Table 3.

Sharpe Ratios for NCREIF under Various Holding-period and Market Conditions

\begin{tabular}{|c|c|c|c|c|c|c|c|}
\hline \multirow{2}{*}{$\begin{array}{l}\text { Real Estate } \\
\text { Indexes }\end{array}$} & \multirow{2}{*}{$\begin{array}{l}\text { Expected } \\
\text { TOM }\end{array}$} & \multicolumn{6}{|c|}{ Holding Period (in years) } \\
\hline & & 3 & 4 & 5 & 6 & 7 & 8 \\
\hline \multirow[t]{6}{*}{ NCREIF Overall } & 4 months & 0.32 & 0.28 & 0.25 & 0.23 & 0.22 & 0.20 \\
\hline & 6 months & 0.30 & 0.27 & 0.25 & 0.23 & 0.21 & 0.20 \\
\hline & 8 months & 0.29 & 0.26 & 0.24 & 0.22 & 0.21 & 0.20 \\
\hline & 10 months & 0.28 & 0.26 & 0.24 & 0.22 & 0.21 & 0.20 \\
\hline & 12 months & 0.27 & 0.25 & 0.23 & 0.22 & 0.20 & 0.19 \\
\hline & 14 months & 0.26 & 0.24 & 0.22 & 0.21 & 0.20 & 0.19 \\
\hline \multirow[t]{6}{*}{ Industrial } & 4 months & 0.33 & 0.29 & 0.27 & 0.25 & 0.23 & 0.22 \\
\hline & 6 months & 0.32 & 0.29 & 0.26 & 0.24 & 0.23 & 0.21 \\
\hline & 8 months & 0.32 & 0.28 & 0.26 & 0.24 & 0.23 & 0.21 \\
\hline & 10 months & 0.31 & 0.28 & 0.26 & 0.24 & 0.22 & 0.21 \\
\hline & 12 months & 0.30 & 0.28 & 0.25 & 0.24 & 0.22 & 0.21 \\
\hline & 14 months & 0.30 & 0.27 & 0.25 & 0.23 & 0.22 & 0.21 \\
\hline \multirow[t]{6}{*}{ Office } & 4 months & 0.23 & 0.20 & 0.18 & 0.17 & 0.16 & 0.15 \\
\hline & 6 months & 0.22 & 0.20 & 0.18 & 0.17 & 0.16 & 0.15 \\
\hline & 8 months & 0.22 & 0.20 & 0.18 & 0.17 & 0.15 & 0.15 \\
\hline & 10 months & 0.21 & 0.19 & 0.18 & 0.16 & 0.15 & 0.14 \\
\hline & 12 months & 0.21 & 0.19 & 0.18 & 0.16 & 0.15 & 0.14 \\
\hline & 14 months & 0.21 & 0.19 & 0.17 & 0.16 & 0.15 & 0.14 \\
\hline \multirow[t]{6}{*}{$\overline{\text { Retail }}$} & 4 months & 0.34 & 0.31 & 0.28 & 0.26 & 0.24 & 0.23 \\
\hline & 6 months & 0.34 & 0.30 & 0.28 & 0.25 & 0.24 & 0.22 \\
\hline & 8 months & 0.33 & 0.30 & 0.27 & 0.25 & 0.24 & 0.22 \\
\hline & 10 months & 0.32 & 0.29 & 0.27 & 0.25 & 0.23 & 0.22 \\
\hline & 12 months & 0.32 & 0.29 & 0.27 & 0.25 & 0.23 & 0.22 \\
\hline & 14 months & 0.31 & 0.28 & 0.26 & 0.24 & 0.23 & 0.22 \\
\hline \multirow[t]{6}{*}{ Apartment } & 4 months & 0.42 & 0.37 & 0.34 & 0.31 & 0.29 & 0.28 \\
\hline & 6 months & 0.41 & 0.37 & 0.34 & 0.31 & 0.29 & 0.27 \\
\hline & 8 months & 0.40 & 0.36 & 0.33 & 0.31 & 0.29 & 0.27 \\
\hline & 10 months & 0.39 & 0.35 & 0.33 & 0.30 & 0.28 & 0.27 \\
\hline & 12 months & 0.38 & 0.35 & 0.32 & 0.30 & 0.28 & 0.27 \\
\hline & 14 months & 0.37 & 0.34 & 0.32 & 0.30 & 0.28 & 0.26 \\
\hline
\end{tabular}

Note: This table displays the real estate Sharpe Ratios based on Equation (21). The data are quarterly NCREIF property indices from 1978Q1 to 2007Q2. The risk-free rate is obtained from Ken French's website. For the period analyzed, the average quarterly risk-free rate is $0.59 \%$. The shaded area corresponds to the more typical holding-period of commercial real estate.

Some readers may observe in Table 3 that the Sharpe ratio for shorter-run investments is more attractive than for the long-run, and conclude that it is more advantageous to invest in real estate for the short-run. Unfortunately, this seemingly shortrun advantage is elusive simply due to the high transaction costs that prevent frequent trading of real properties. Real estate is known for its high transaction costs. Collett et al (2003) 
report that the average round-trip cost of buying and selling commercial properties in the U.K. is about $7 \%$ to $8 \%$ of the asset's value. This cost can only be amortized over longer periods so that the price appreciation net of transaction cost satisfies the investor's objective and justifies the risk. That is why most large institutional investors typically hold their portfolios in private real estate for about five to eight years. ${ }^{16}$

\section{Conclusions}

Performance comparison between real estate and financial assets like common stocks has for years led many real estate researchers to conclude that real estate is a "low risk, high return” asset class that deserves a much bigger role in the institutional mixed-asset portfolios. In this paper, we have found that the seemingly superior risk-adjusted return of real estate is an illusion caused by inappropriate risk measurement. We show that there are two fundamental problems in applying the conventional risk measure to real estate without any modification with regard to the unique characteristics of real estate. First, the real estate market is inefficient, and property return volatility is holding-period dependent, in contrast to the constant return volatility implied by the i.i.d assumption. Therefore, it is inappropriate to evaluate real estate risk using the conventional single-period performance measure. Second, in addition to the price risk, real estate investors also face the uncertainty of time-on-market. This illiquidity risk is unique to real estate, and it is inadequate to ignore this part of real estate risk in real estate performance measurement.

\footnotetext{
${ }^{16}$ It can be argued that transaction costs reduces investment returns and can cause the real estate Sharpe ratios in Table 3 to be lower. However, this effect is more pronounced over shorter holding-period but less significant over longer holding-period. For example, an $8 \%$ transaction over 8 year holding-period averages about $0.25 \%$ per quarter return reduction, which will not change the Sharpe ratios significantly.
} 
The main contribution of this paper is that we develop a modified performance measure — a Sharpe ratio for real estate — to overcome the inadequacy of using the conventional Sharpe ratio to measure the risk-adjusted return of real estate. Our modified Sharpe ratio captures the time-dependent nature of real estate risk by incorporating illiquidity risk in a closed-form formula. Our finding shows that, once the real estate risk is properly measured, the long-standing "real estate risk premium puzzle” no longer exists.

A noteworthy feature of our modified Sharpe ratio is that we do not resort to any particular distribution to replace the prevailing i.i.d. assumption for real estate. Instead, we take advantage of the linear pattern of real estate price volatility growth over time, and obtain the risk structure of real estate through a simple regression (Equation (7)). Our modified Sharpe ratio, therefore, is better rooted in empirical evidence.

As a final note, it might appear to some that, since we have provided an integrated risk measure for real estate (Equation 17), one can simply use this measure to adjust real estate risk and return and re-examine the real estate allocation in mixed-asset portfolios by running the classical mean-variance analysis. While this is certainly a tempting idea, it is necessary to realize that the classical MPT is based on single-period utility maximization, while real estates are typically held for multiple periods. Given the non-i.i.d. nature of real estate, the proper inputs to the MPT (mean and variance) are those measured at the optimal holding period. In other words, mixed-asset portfolio must be optimized for both portfolio weights as well as holding period based on multi-period utility maximization. This implies a fundamental departure from the classical MPT. Optimal asset allocation in such a framework, therefore, requires a new analytical model that extends the classical mean-variance beyond single-period utility maximization. 


\section{Appendix A}

Assume holding periods are $T$ quarters and $r_{f}$ is the quarterly return of a risk-free asset. By definition, we can express both quarterly and annual Sharpe ratios as follows,

Quarterly Sharpe Ratio (QSR):

$$
Q S R=\frac{u_{T} / T-r_{f}}{\sqrt{\sigma_{T}^{2} / T}}
$$

Annual Sharpe ratio (ASR):

$$
A S R=\frac{\frac{u_{T}}{(T / 4)}-4 r_{f}}{\sqrt{\frac{\sigma_{T}^{2}}{(T / 4)}}}
$$

Simplifying Equation (A.2) results in,

$$
A S R=2 \frac{u_{T} / T-r_{f}}{\sqrt{\sigma_{T}^{2} / T}}
$$

Equations (A.1) and (A.3) suggests that the annual Sharpe ratio is always twice as the quarterly Sharpe ratio.

Suppose that the expected quarterly return and volatility as $u$ and $\sigma$, respectively. When returns are i.i.d., we have

$$
\begin{aligned}
& u_{T}=T u \\
& \sigma_{T}^{2}=T \sigma^{2}
\end{aligned}
$$

Inserting (A.4) into Equations (A.1) and (A.3) yields

$$
Q S R=\frac{u-r_{f}}{\sigma} \text { and } A S R=2 \frac{u-r_{f}}{\sigma}
$$

Therefore, both the quarterly and annual Sharpe ratios do not vary over holding periods under the i.i.d. assumption, which is a well-known result. 


\section{References}

Bond, S., S. Hwang, Z. Lin and K. Vandell (2007), "Marketing Period Risk in a Portfolio Context: Theory and Empirical Estimates from the UK Commercial Real Estate Market?” Journal of Real Estate Finance and Economics 34: 447-461.

Brown, R. and T. Geurts (2005), "Private Investor Holding Period,” Journal of Real Estate Portfolio Management 11: 93-104.

Campbell, J. (1987), “Stock returns and the term structure”, Journal of Financial Economics 18, 373-399.

Campbell, J. (1991), “A variance decomposition for stock returns”, The Economic Journal 101, 157-179.

Case, K. and R. Shiller (1989), “The Efficiency of the Market for Single-Family Homes,” American Economic Review 79, p125-137.

Cheng, P., Z. Lin, and Y. Liu (2008), “A Model of Time-on-market and Real Estate Price under Sequential Search with Recall,” Real Estate Economics 36, 813-843.

Cole, R., D. Guilky, and M. Miles (1986), “Toward an Assessment of the Reliability of Commercial Appraisals,” The Appraisal Journal 54(3), 422-432.

Collett D., C. Lizieri, and C. Ward (2003), “Timing and the Holding Periods of Institutional Real Estate,” Real Estate Economics, 31 (2), 205-222.

Dotzour, M. (1988), “Quantifying Estimation Bias in Residential Appraisal,” Journal of Real Estate Research 3(3), 1-11.

Englund, P., T. Gordon, and J. Quigley (1999), “The Valuation of Real Capital: A Random Walk down Kungsgatan,” Journal of Housing Economics 8, 205-216.

Fama, E., (1970) "Multi-period Consumption-Investment Decisions”, American Economic Review, 163- 174.

Fama, E. and K. French (1988), “Dividend yields and expected stock returns”, Journal of Financial Economics 22, 3-27.

Fama, E. and K. French (1989), "Business conditions and expected returns on stocks and bonds”, Journal of Financial Economics 25, 23-49.

Gau, G. and K. Wang (1990), “Capital Structure Decisions in Real Estate Investment,” AREUEA Journal 18:501-521. 
Geltner, D. and W. Goetzmann (2000), “Two Decades of Commercial Property Returns: A Repeated-Measures Regression - Based Version of the NCREIF Index”, Journal of Real Estate Finance and Economics, 5-21.

Goetzmann, W. and R. Dhar (2005), “Institutional Perspectives on Real Estate Investing: The Role of Risk and Uncertainty,” Yale ICF Working Paper No. 05-20

Ibbotson, R. and L. Siegel (1984), "Real Estate Returns: A Comparison with Other Investments,” Real Estate Economics 12(3), 219-42.

Keim, D. and R. Stambaugh (1986), "Predicting Returns in the Stock and Bond Markets,” Journal of Financial Economics 17, 357-390.

Leung, C. (2007), “Equilibrium Correlations of Asset Price and Return,” Journal of Real Estate Finance and Economics 34, 233-256.

Lin, Z. and Y. Liu (2008), "Real Estate Returns and Risk with Heterogeneous Investors,” Real Estate Economics 36, 753-776.

Lintner, J. (1965), “The valuation of risk assets and the selection of risky investments in stock portfolios and capital budgets”, Review of Economics and Statistics, 47 (1), 13-37.

Lippman, S. and McCall J. (1986), “An Operational Measure of Liquidity,” American Economic Review 76, 43-55.

Markowitz, H. (1952), “Portfolio Selection,” Journal of Finance, 12, 77-91

Merton, R. (1969), "Lifetime Portfolio Selection under Uncertainty: The Continuous Time Model," Review of Economics and Statistics, 51, 247-257.

Ross S. (2002), A First Course in Probability, Sixth Edition, Prentice-Hall, Inc.

Samuelson, P.A. (1969), "Lifetime Portfolio Selection by Dynamic Stochastic

Programming,” Review of Economics and Statistics, 51, 239-246

Sharpe, W. F. (1964), “Capital Asset Prices: A Theory of Market Equilibrium under Conditions of Risk,” Journal of Finance, (September) 425-442

Sharpe, W. (1966), “Mutual Fund Performance,” Journal of Business, Vol. 39, 119-138

Sharpe, W. (1994), “The Sharpe Ratio,” Journal of Portfolio Management, Issue 1, 49-58

Wang, P. (2006), "Errors in Variables, Links between Variables and Recovery of Volatility Information in Appraisal-Based Real Estate Return Indexes,” Real Estate Economics 34(4), 497-518. 
Young, M. and Graff, R. (1995), "Real Estate is Not Normal: A Fresh Look at Real Estate Return Distributions,” Journal of Real Estate Finance and Economics 10, 225-259.

Young, M. (2008), Revisiting Non-normal Real Estate Return Distributions by Property Type in the U.S. Journal of Real Estate Finance and Economics, 36, 233-248. 